\title{
Study on Prescribing Pattern among the Outpatients with Eczema in the Dermatology Department of a Tertiary Care Teaching Hospital
}

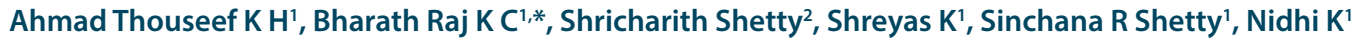 \\ 'Department of Pharmacy Practice, NGSM Institute of Pharmaceutical Sciences, NITTE (Deemed to be University), Deralakatte, Mangaluru, Karnataka, INDIA. \\ ${ }^{2}$ Department of Dermatology, Justice K.S. Hegde Charitable Hospital, NITTE (Deemed to be University), Deralakatte, Mangaluru, Karnataka, INDIA.
}

\begin{abstract}
Background: Eczema is a chronic, usual, non-infective inflammatory state characterized by intense pruritis, redness, and swelling. Eczema patients experience mild to severe systemic symptoms such as itching, pain, and sleep disturbances, resulting in a significantly diminished quality of life. Methods: This prospective observational study was conducted for six months to study the prescribing pattern of various drugs in eczema patients in the outpatient department of dermatology. 86 anti-eczema prescriptions were analyzed. Factors considered were age, gender, types of diagnosis, site of the disease, and anti-eczema drugs prescribed. Results: Out of 86 patients, females $(53.5 \%)$ were more than males $(46.5 \%)$. The majority of the patients $(44.18 \%$ ) belonged to the age group 21 to 40 years and allergic contact dermatitis was the most common (39.53\%) and most commonly affected was lower limb (43.02\%). Most drugs prescribed were topical agents $(60.38 \%)$ when compared to oral drugs $(39.62 \%)$. Antihistamines $(37.68 \%)$ were found to be the most commonly prescribed medication
\end{abstract}

class. Levocetirizine $(25.60 \%)$ was the most common drug prescribed in this study. Most of the prescriptions contained at least two drugs (61.63\%). Conclusion: A clinical pharmacist can help improve a patient's quality of life by assisting with prescription analysis and prescribing patterns. Studies can assist in providing feedback to physicians on current prescribing practices.

Key words: Prescribing pattern, Anti-eczema drugs, Levocetirizine, Eczema, Dermatology.

Correspondence

Mr. Bharath Raj K C,

Assistant Professor, NGSM Institute of Pharmaceutical Sciences, Nitte (Deemed to be University), Mangaluru-575 018, Karnataka, INDIA.

Email id: bharathraj@nitte.edu.in

DOI: 10.5530/jyp.2022.14.20

\section{INTRODUCTION}

The biggest organ in the human body is the skin. The overall ecosystem of the place, including socio-cultural milieu, geography, nutrition, genetics, and so on, influences the prevalence and pattern of skin diseases. Through hospital-based studies, certain attempts have been made to categorize skin diseases. ${ }^{1}$

Eczema narrates a number of inflammatory skin disorders. It is a chronic, usual, non-infective inflammatory state characterized by intense pruritis, redness, and swelling. ${ }^{2}$ It has a prevalence of up to $20 \%$ in children and $5 \%$ in adults worldwide. ${ }^{3}$ Eczema and dermatitis are two words that are used synonymously. ${ }^{2}$ Adults can encounter various types of eczema such as asteatotic eczema, eczematous drug eruptions, varicose eczema, lichen simplex, atopic eczema, contact dermatitis, nummular eczema, seborrheic eczema, photosensitive eczema, pompholyx eczema. ${ }^{4}$ Patients with eczema suffer from mild local to severe systemic symptoms such as itch, pain, sleep disturbance, leading to substantially reduced quality of life. ${ }^{3}$ The goals for the treatment of eczema include repairing and maintaining good skin integrity, alleviating symptoms, and improving the quality of life. ${ }^{4}$ The induction treatment options for eczema include topical corticosteroids and topical tacrolimus. The maintenance treatment includes proactive therapy with topical anti-inflammatory drugs and topical corticosteroids or topical tacrolimus intermittently. Use topical anti-inflammatory drugs at earliest signs of local recurrence. Therapy for complications of eczema such as bacterial infections include oral and/ or topical antibiotics, and viral infections include oral and/or topical antiviral drugs. Treatment of severe refractory disease includes potent topical corticosteroids, combination therapy with oral cyclosporine, combination therapy with ultraviolet therapy, combination therapy with psychosomatic therapy. Adjuvant therapy includes oral antihistamines, identification of trigger factors, and psychosomatic approach. ${ }^{5}$ The purpose of this study was to gather insight regarding the prescribing pattern of various drugs in eczema patients in the outpatient department of dermatology.

Even though medicines are among the therapeutic interventions that will promote improved health to the patients, rational use of those medications prescribed plays a major role in providing the therapeutic intervention that is efficient and sufficient. Rational use of medications means that the individual will receive the right medicine with adequate dose in the adequate duration of time at affordable cost, which also includes appropriate information with follow up. ${ }^{6}$ Prescription pattern monitoring studies form the main tool in the assessment of prescribing, dispensing and distributing medicines to carry out rational use of medicines. This pattern will facilitate the appropriate use of drugs and decrease drug misuse as much as possible. ${ }^{7}$ Also, the rational use of the drugs is necessary by the health care provider to avoid several clinical consequences caused by the misuse of the drug. Periodic auditing of the prescriptions to assess and monitor prescription pattern in eczema patients provide a tool to enhance the efficacy of the treatment, minimize the adverse effects causing and also optimize the cost of treatment by providing useful feedback to the health care provider. $^{8}$

This is an open access article distributed under the terms of the Creative Commons Attribution-NonCommercial-ShareAlike 4.0 License, which allows others to remix, tweak, and build upon the work non-commercially, as long as the author is credited and the new creations are licensed under the identical terms. 


\section{MATERIALS AND METHODS}

The study was carried out in the dermatology department of Justice K.S. Hegde Charitable Hospital, a tertiary care teaching hospital in Mangaluru, Karnataka, India

A prospective observational study was conducted for six months from October 2020 - March 2021 to study the prescribing pattern of various drugs in eczema patients in the outpatient department of dermatology after obtaining approval from the Institutional ethics committee (Ref No-NGSMIPS/IEC/05/2020), The minimum sample size of the study was determined to be 86 . All outpatients diagnosed with eczema above 18 years and prescribed with a minimum of two drugs per prescription were included. Patients with unclear data were excluded in this study, including pregnant women and lactating women, patients who were not willing to give consent.

Prescriptions were reviewed, and necessary data were collected, including age, gender, diagnosis, disease site, drug name, class of drug, and frequency.

A suitable data collection form was designed to collect and document the data. Patients' information was gathered by using patient case notes and patient prescriptions. Patients' demographic parameters such as age and gender were considered for clinical presentation. Prescribing patterns of the anti-eczema drugs were analysed by collecting the details of drug usage, including frequency, dose, and route of administration. Finally, the results were analysed using descriptive statistical methods.

\section{RESULTS}

\section{Gender-wise distribution}

Out of 86 patients, 46 females (53\%) and 40 were males (47\%). Female patients were predominant compared to the male patient population in the study. The details are summarized in Table 1.

\section{Age-wise distribution}

Most patients were found between the age category of 21-40 years with 38 patients $(44.18 \%)$, followed by the 25 patients $(29.06 \%)$ in the age group of 18-20 years. The details are summarized in Table 1.

\section{Types of Eczema}

Allergic contact dermatitis was the most common type of eczema (39 patients, 39.53\%) among the study population, followed by atopic eczema (31 patients, $36.05 \%$ ). The details are summarized in Table 1.

\section{Site of the disease}

The most common site was the lower limbs in 37 patients $(43.02 \%)$, followed by the upper limbs in 23 patients $(26.74 \%)$. The details are summarized in Table 1.

\section{Route of administration}

207 drugs were prescribed to 86 patients, of which 125 (60.39\%) were topical agents and $82(39.61 \%)$ were oral agents. The details are summarized in Table 2 .

\section{Drugs prescribed in the study population}

Antihistamines 78 (37.68\%) was found to be a largely prescribed class of drug, which was then followed by topical corticosteroids 47 (22.71\%), moisturizers 29 (14.01\%), topical corticosteroids + antibiotics $29(14.01 \%)$, antibiotics $10(4.83 \%)$, antifungals 7 (3.38\%), topical corticosteroids + antifungals 5 (2.42\%) and oral corticosteroids $2(0.96 \%)$. In the study population, levocetirizine was the highly prescribed drug 53 (25.60\%) then followed by liquid paraffin 29 (14.01\%). The details are summarized in Table 2 .
Table 1: Demographics, eczema type, eczema site.

\begin{tabular}{|c|c|}
\hline Criteria & Frequency (Percentage) \\
\hline \multicolumn{2}{|l|}{ Gender } \\
\hline Male & $40(46.5)$ \\
\hline Female & $46(53.5)$ \\
\hline \multicolumn{2}{|l|}{ Age in Years } \\
\hline $18-20$ & $25(29.06)$ \\
\hline $21-40$ & $38(44.18)$ \\
\hline $41-60$ & $17(19.76)$ \\
\hline $61-80$ & $6(6.97)$ \\
\hline \multicolumn{2}{|l|}{ Type of Eczema } \\
\hline Feet Eczema & $4(4.65)$ \\
\hline Nummular Eczema & $7(8.14)$ \\
\hline Allergic Contact Dermatitis & $34(39.53)$ \\
\hline Atopic Eczema & $31(36.05)$ \\
\hline Seborrheic Eczema & $7(8.14)$ \\
\hline Chronic Eczema & $2(2.33)$ \\
\hline Subacute Eczema & $1(1.16)$ \\
\hline \multicolumn{2}{|l|}{ Site of Eczema } \\
\hline Upper Limb & $23(26.74)$ \\
\hline Lower Limb & $37(43.02)$ \\
\hline Face & $7(8.14)$ \\
\hline Neck & $7(8.14)$ \\
\hline Scalp & $6(6.98)$ \\
\hline Back & $6(6.98)$ \\
\hline
\end{tabular}

\section{Distribution based on number of drugs per prescription}

Out of 86 patients, most of them were prescribed two drugs (53 patients, $61.63 \%$ ), followed by three drugs (29 patients, 33.72\%). Only four patients $(4.65 \%)$ have been prescribed four drugs.

\section{DISCUSSION}

This study included 86 outpatients of either gender, above 18 years. The study's main goal was to study the prescribing pattern of various drugs in eczema patients in the outpatient department of dermatology of a tertiary care teaching hospital.

In this study, it is found that out of 86 outpatients, the majority of the study populations are females (46 patients 53.5\%) compared to males (40 patients, $46.5 \%$ ). Similar results were obtained from a study done by Vemuri VR et al., which showed that most were females (151 patients, $62 \%$ ), less than half (94 patients, $38 \%$ ) of them were males. ${ }^{9}$ Another research conducted by Divyashanthi CM et al., also showed a predominance of female patients (48 patients, 59.26\%) over male patients (33 patients, $40.74 \%){ }^{10}$

In this study, the maximum number of patients are seen within 21 to 40 years. (38 patients, $44.18 \%$ ). A similar result was obtained from a study directed by Giri VP et al., with the highest number of patients (80 patients) seen in the age group of 21 to 40 years. ${ }^{11}$ In another study conducted by Vemuri VR et al., the higher number (63 patients, 25.71\%) with the onset of eczema was 20-29 years old. ${ }^{9}$ Also, in another study organized by Abraham MS et al., most patients (36.17\%) belong to 18 to 40 years. ${ }^{12}$

The most common site involved was the lower limb (37 patients, $43.02 \%$ ). A similar result has been seen in the study directed by Scaria $\mathrm{S}$ et al., where extensor surfaces $(80 \%)$ were mostly affected surfaces. ${ }^{13}$ In the current study, out of 207 drugs prescribed to 86 patients, antihistamines 
Table 2: Route of administration, drug category and drugs prescribed in the study population.

\begin{tabular}{|c|c|c|c|}
\hline $\begin{array}{c}\text { Route of } \\
\text { administration } \\
\text { (Frequency, } \\
\text { Percentage) }\end{array}$ & Drug category & Drugs & $\begin{array}{l}\text { Frequency } \\
\text { (Percentage) }\end{array}$ \\
\hline \multirow{22}{*}{$\begin{array}{c}\text { Topical } \\
(125,60.39)\end{array}$} & Moisturizers & Liquid paraffin & $29(14.01)$ \\
\hline & \multirow{6}{*}{ Corticosteroids } & Mometasone & $11(5.31)$ \\
\hline & & Clobetasol & $17(8.21)$ \\
\hline & & Desonide & $6(2.90)$ \\
\hline & & Fluticasone & $11(5.31)$ \\
\hline & & propionate & $2(0.97)$ \\
\hline & & Betamethasone & \\
\hline & \multirow{2}{*}{ Antifungals } & Ketoconazole & $6(2.90)$ \\
\hline & & Luliconazole & $1(0.48)$ \\
\hline & \multirow{8}{*}{$\begin{array}{l}\text { Corticosteroids + } \\
\text { Antibiotics }\end{array}$} & Betamethasone + & $9(4.35)$ \\
\hline & & Fusidic acid & $7(3.38)$ \\
\hline & & Clobetasone + & $1(0.48)$ \\
\hline & & $\begin{array}{c}\text { Mirconazore } \\
\text { Clobetasol + Fusidic }\end{array}$ & $5(2.41)$ \\
\hline & & $\begin{array}{l}\text { Cid } \\
\text { acid }\end{array}$ & $2(0.97)$ \\
\hline & & $\begin{array}{l}\text { Fluticasone } \\
\text { propionate }+ \\
\text { Mupirocin }\end{array}$ & $5(2.41)$ \\
\hline & & $\begin{array}{l}\text { Hydrocortisone + } \\
\text { Fusidic acid }\end{array}$ & \\
\hline & & $\begin{array}{l}\text { Mometasone }+ \\
\text { Fusidic acid }\end{array}$ & \\
\hline & \multirow{3}{*}{$\begin{array}{l}\text { Corticosteroids + } \\
\text { Antifungals }\end{array}$} & Mometasone + & $2(0.97)$ \\
\hline & & Clotrimazole & $3(1.45)$ \\
\hline & & $\begin{array}{c}\text { Beclomethasone }+ \\
\text { Clotrimazole }\end{array}$ & \\
\hline & \multirow{2}{*}{ Antibiotics } & Fusidic acid & $6(2.90)$ \\
\hline & & Mupirocin & $2(0.97)$ \\
\hline \multirow{6}{*}{$\begin{array}{l}\text { Oral agents } \\
(82,39.61)\end{array}$} & \multirow{4}{*}{ Antihistamines } & Levocetirizine & $53(25.60)$ \\
\hline & & Cetirizine & $2(0.97)$ \\
\hline & & Desloratadine & $22(10.63)$ \\
\hline & & Hydroxyzine & $1(0.48)$ \\
\hline & Corticosteroids & Methyl prednisolone & $2(0.97)$ \\
\hline & Antibiotics & $\begin{array}{l}\text { Amoxicillin }+ \\
\text { Clavulanic acid }\end{array}$ & $2(0.97)$ \\
\hline
\end{tabular}

were the largest class $(78,37.68 \%)$ of drugs, followed by topical corticosteroids $(47,22.71 \%)$. A similar result has been seen in the study organized by Vemuri Vemuri et al. The largest group of drugs given were antihistamines, 221 out of 703 total drugs. ${ }^{9}$ In a study conducted by Scaria $\mathrm{S}$ et al., there was a contrast in the result, that the majority of patients were prescribed with emollients (95\%) followed by antihistamines (75\%) and topical corticosteroids (75.0\%). ${ }^{13}$ In another study organized by Pona A et al., the highest class of drugs prescribed were topical corticosteroids (59\%) followed by moistures (12\%). ${ }^{14}$ In another study conducted by Divyashanthi CM et al., topical and systemic corticosteroids were the most commonly advised drugs (45.54\%), followed by antihistamines $(30.69 \%){ }^{10}$ Antihistamines were most commonly prescribed in our study because they play an important role in the management of eczema. In the present study, levocetirizine $(25.60 \%)$ was the most commonly prescribed drug, followed by liquid paraffin (14.01\%). A similar result has been observed in a study organized by Vemuri VR et al., where levocetirizine was the most commonly commanded antihistamines. ${ }^{9}$ In another study done by Divyashanthi CM et al., the contrast in result has been seen where the most commonly prescribed antihistamine drug was cetirizine $(54.83 \%)$ followed by hydroxyzine $(16.12 \%) .{ }^{10}$ In our study, levocetirizine is prescribed frequently because it is considered to have less sedative effect compared to cetirizine. In this study, the most commonly prescribed topical corticosteroid was found to be clobetasol (8.21\%), followed by mometasone $(5.31 \%)$ and fluticasone propionate $(5.31 \%)$. The other study directed by Divyashanthi $\mathrm{CM}$ et al., showed a divergence in result, where the most commonly given topical corticosteroid was desonide $(55.56 \%)$ followed by mometasone $(33.33 \%)$ and clobetasol $(6.17 \%) .{ }^{10}$ The selection of a particular drug must be based on its efficacy and potency, by the size of the lesion, the location of eczema.

In the present study, out of 86 patients, most patients were given two drugs (53 patients, 61.63\%) followed by three drugs (29 patients, $33.72 \%)$, and only four patients were prescribed four (4.65\%) drugs. In a study conducted by Abraham MS et al., a contrast result was obtained where the majority number of patients have prescribed three drugs (50.35\%) followed by two drugs (24.46\%). ${ }^{12}$ In another study directed by Kumar MA et al., most patients have been prescribed three (29.26\%) drugs followed by four (24.39\%). ${ }^{15}$

\section{CONCLUSION}

Prescribing pattern studies have become a significant tool for assessing healthcare systems. This study mainly focused on the prescribing patterns of anti-eczema drugs prescribed for eczema patients in the outpatient department of dermatology. In this study, females (53.5\%) were predominant than males $(46.5 \%)$. It was observed that the most affected patients were in the age between 21 and 40 years (44.18\%). It was found that allergic contact dermatitis was the most common type of eczema $(39.53 \%)$ found in the study population. It was also seen that lower limbs were the highly affected site of disease $(43.02 \%)$, and levocetirizine $(25.60 \%)$ was the most commonly prescribed drug for the treatment. In this study, topical $(60.39 \%)$ and oral $(39.61 \%)$ drugs for eczema were prescribed, including liquid paraffin, levocetirizine, mometasone, desloratadine, clobetasol fluticasone propionate, etc. respectively. This study concluded that careful and judicious use of antieczema drugs would allow better patient management and limit the endpoint morbidity and mortality arising from eczema. Therefore, there is a need for educational programs to facilitate rational use of anti-eczema drugs and promote accessible resources. A clinical pharmacist can be involved in prescription analysis and prescribing patterns, improving the patient's quality of life. Studies can help provide feedback to physicians on contemporary prescribing practices.

\section{ACKNOWLEDGEMENT}

We authors would like to thank NITTE (Deemed to be University), Justice K. S. Hegde Charitable Hospital and N.G.S.M Institute of Pharmaceutical Sciences, Mangaluru, Karnataka for providing us with all the necessary facilities for carrying out this work.

\section{CONFLICT OF INTEREST}

The authors declare that there is no conflict of interest.

\section{REFERENCES}

1. Singhal RR, Talati KN, Gandhi BP, Shinde MK, Nair PA, Phatak AG. Prevalence and Pattern of Skin Diseases in Tribal Villages of Gujarat: A Teledermatology Approach. Indian J Community Med. 2020;45(2):199-203. doi: 10.4103/ijcm. IJCM_76_19. PMID 32905082.

2. Peate I. Eczema: Causes, symptoms and treatment in the community. $\mathrm{Br} \mathrm{J}$ Community Nurs. 2011:16(7):324, 326-31. doi: 10.12968/bjen.2011.16.7.324. PMID 21727789.

3. Siegels D, Heratizadeh A, Abraham S, Binnmyr J, Brockow K, Irvine AD, et al. European Academy of Allergy, Clinical Immunology Atopic Dermatitis Guideline 
group. Systemic treatments in the management of atopic dermatitis: A systematic review and meta-analysis. Allergy. 2021;76(4):1053-76. doi: 10.1111/ all.14631, PMID 33074565

4. Burr S. Assessment and management of eczema in adults in the community setting. Br J Community Nurs. 2019;24(3):110-5. doi: 10.12968/ bjcn.2019.24.3.110, PMID 30817210.

5. Katoh N, Ohya Y, Ikeda M, Ebihara T, Katayama I, Saeki H, et al. Committee for Clinical Practice Guidelines for the Management of Atopic Dermatitis 2018, The Japanese Society of Allergology, The Japanese Dermatology Association. Japanese guidelines for atopic dermatitis 2020. Allergol Int. 2020;69(3):356-69. doi: 10.1016/j.alit.2020.02.006, PMID 32265116.

6. Karimi A, Haerizadeh M, Soleymani F, Haerizadeh M, Taheri F. Evaluation of medicine prescription pattern using World Health Organization prescribing indicators in Iran: A cross-sectional study. J Res Pharm Pract. 2014;3(2):39-45. doi: 10.4103/2279-042X.137058, PMID 25114935.

7. Jain S, Upadhyaya $P$, Goyal J, Kumar A, Jain P, Seth $V$, et al. A systematic review of prescription pattern monitoring studies and their effectiveness in promoting rational use of medicines. Perspect Clin Res. 2015;6(2):86-90. doi: 10.4103/2229-3485.154005, PMID 25878953.

8. Gupta S, Singh S, Rathore PK. Analysis of antibiotics prescribed to patients attending dermatology OPD of a teaching hospital in Rohilkhand region. J Pak Assoc Dermatol. 2021;31(2):211-8.

9. Vemuri VR, Nayak UV. Drug utilization study of atopic dermatitis in a tertiary care hospital. Int J Basic Clin Pharmacol. 2016;5:2061-5. doi: 10.18203/2319-2003. IJBCP20163236.

10. M. D, Kolasani BP, Jayabal P, Sasidharan P, Datchanamurthy B. WHO core prescribing indicators in patients with allergic contact dermatitis in a coastal town of South India. Int J Basic Clin Pharmacol. 2017;6(1):61-5. doi: 10.18203/2319-2003.ijbcp20164508.

11. Giri VP, Giri OP, Kanodia S. A study on drug Prescription pattern in Allergic contact dermatitis at Tertiary Care Teaching Hospital in South India. JEMDS. 2014;3(43):10683-8. doi: 10.14260/jemds/2014/3392.

12. Abraham MS, Sajeeth $\mathrm{Cl}$, Sreeja PA, Abraham BT. Drug utilization evaluation of corticosteroids in Dermatology Department of a tertiary care teaching hospital at Palakkad, Kerala. Int J Health Sci Res. 2016;6(6):130-6.

13. Scaria $S$, James $E$, Dharmaratnam AD. Epidemiology and treatment pattern of atopic dermatitis in patients attending a tertiary care teaching hospital. Int J Res Pharm Sci. 2011;2(1):38-44.

14. Pona A, Cline A, Kolli S, Feldman SF, Fleischer AFJ. Prescribing patterns for atopic dermatitis in the United States. J Drugs Dermatol. 2019;18(10):987-90. PMID 31584776.

15. Kumar MA, Noushad PP, Shailaja K, Jayasutha J, Ramasamy C. A study on drug prescribing pattern and use of corticosteroids in dermatological conditions at a tertiary care teaching hospital. Int J Pharm Sci Rev Res. 2011;9(2):132-5.

Article History: Received: 28-10-2021; Revised: 08-11-2021; Accepted: 12-12-2021

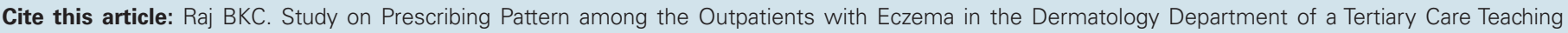
Hospital. J Young Pharm. 2022;14(1):106-9. 